\title{
Prevalence of Acute Kidney Injury in Patients with Perinatal Asphyxia in Tertiary Hospital
}

\section{Nisha Jyoti Shrestha ${ }^{1}$, Kalpana Upadhaya Subedi ${ }^{1}$, Shristy Shakya ${ }^{2}$ and Saroja Adhikari ${ }^{3}$}

${ }^{1}$ Department of Paediatrics, National Academy of Medical Sciences, Kathmandu, Nepal

${ }^{2}$ Department of Neonatology, Paropakar Maternity and Women's Hospital, Kathmandu, Nepal

${ }^{3}$ Saroja Adhikari, Analyst, Digital Data System for Development, Kathmandu, Nepal

\author{
Correspondence: \\ Nisha Jyoti Shrestha \\ Department of Paediatrics \\ National Academy of Medical Sciences \\ Kathmandu, Nepal \\ E-mail: nishajyoti@hotmail.com
}

DOI:10.3126/jnps.v39i2.27983

Submitted on: 2020-03-09

Accepted on: 2020-04-15

Acknowledgements: None

Funding: Nil

Conflict of Interest: None declared

Permission form IRB: Yes

To cite this article: Shrestha NJ, Subedi KU, Shakya Shristy, Adhikari Saroja. Prevalence of Acute Kidney Injury in Patients with Perinatal Asphyxia in Tertiary Hospital. J Nepal Paediatr Soc. 2019;39(2):109-15.

\section{ABSTRACT}

Introduction: Perinatal asphyxia has multisystem involvement, kidneys are most frequently affected.This study was conducted to determine the relation between severity of Hypoxic Ischaemic Encephalopathy (HIE) with acute kidney injury in term neonates.

Methods: Retrospective study was done over a period of six months (Sept 2016 to Feb 2017) at Department of Neonatology of a tertiary level maternity hospital. Total 98 cases of Perinatal asphyxia cases which were diagnosed with certain degree of HIE were evaluated for its relation with renal involvement in different stage of HIE.

Results: Out of 98 cases of perinatal asphyxia, HIE I was $21 \%$, HIE II was $69 \%$ and HIE III was $10 \%$, among which $72 \%$ cases had some degree of renal problem. seventy two cases had renal problem, oliguric cases were $41(57 \%)$ among which $33 \%$ case had persistent symptoms and associated renal function deterioration. Among 42 cases of deranged RFTs, $40 \%$ of cases has persistently deranged RFTs. In comparison to HIE II in HIE III, $22 \%$ of cases had one time derangement of RFTs and 33\% cases had at least one observation of oliguria, while remaining $45 \%$ cases had persistent deterioration of RFTs and urine output, suggesting that progression in HIE stage has significant association with renal dysfunction $(p<0.05)$. More than half of the cases of HIE III had mortality while $20.3 \%$ of HIE II cases had mortality, indicating that the mortality is highly significant with higher HIE grade $(\mathrm{p}<0.05)$.

Conclusions: Renal involvement is very common in cases of perinatal asphyxia, and severity of renal involvement increases as the HIE grading increases.

Key words: : acute kidney injury; HIE; Oliguria; perinatal asphyxia

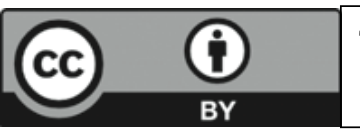

This work is licensed under creative common attribution 3.0 license 


\section{INTRODUCTION}

Perinatal asphyxia (PA) has multi-organ involvement with multiple complications in the neonatal period and beyond. Incidence of perinatal asphyxia is reported as 1 to $1.5 \%$ at various centres. In our country Nepal, perinatal asphyxia is the third commonest cause for neonatal mortality, and also the most preventable cause to decrease neonatal mortality. ${ }^{1}$

During the event of perinatal asphyxia most of the organs are involved and damaged due to hypoxia and ischemia. The most affected organs are the kidneys in $50 \%$ followed by brain in $28 \%$, cardiovascular system (CVS) in $25 \%$ and lungs in $23 \%$ cases. $^{2}$ It is known that kidneys are very delicate and sensitive to hypoxia, renal insufficiency occurs within 24 hours of a hypoxic ischemic event. If the hypoxia and ischemia is prolonged, that event causes irreversible cortical necrosis. ${ }^{2-4}$

In the cases with brain involvement, a stable biochemical environment is utmost important. So, to facilitate appropriate fluid and electrolyte management, early recognition of renal involvement is essential in Hypoxic Ischaemic Encephalopathy (HIE) cases. ${ }^{2,4}$ In neonates it is very difficult to diagnose or to recognise of renal failure in initial state. It is mainly due to influence of maternal biochemical parameters and poorly established biochemical parameters in this age group..$^{2,4}$

It is well recognised that PA is one of the commonest cause of newborn death in our country, ${ }^{1}$ though survival percentage is better than before, associated organ involvement determines the quality of life beyond neonatal period. Thus, we performed this study to determine the occurrence of renal involvement in $\mathrm{PA}$ and to correlate the severity of renal involvement with HIE grading of asphyxiated neonates.

\section{METHODS}

A retrospective study was conducted for a period of six months, in a tertiary level referral hospital of Kathmandu, Nepal, from 2016 Sept to 2017 Feb, where 98 term PA cases born with APGAR score $<3 / 10$ in 1 min and $<7 / 10$ in 5 mins were analysed.
All asphyxiated (as per WHO definition) neonates were selected as cases. Preterm cases, and the cases with incomplete data were excluded from the study. Variables such as gestational age, birth weight, perinatal history, examination findings were recorded in predesigned proforma.

All the cases had first renal function tests drawn after 48 hours of life. Under aseptic precautions, 3 $\mathrm{ml}$ blood was drawn and evaluated for blood urea (Enzymatic Colorimetric Test), serum creatinine (Jaffe's test) and serum electrolytes (Calorimetric method)

Results were recorded in the proforma. Daily vital signs, occurrence of seizures, urine frequency was also noted in proforma. Abnormal creatinine was considered when serum creatinine was elevated two standard deviations above mean value for term gestation or rising $0.3 \mathrm{mg} / \mathrm{dL} / \mathrm{day}^{2}$

Urine output data were extracted from nursing records. Impaired urine output was considered if urine output was $<1 \mathrm{ml} / \mathrm{kg} / \mathrm{hr}$ in catheterised children and less than six wet nappies in uncatheterized children (beyond $12 \mathrm{hrs}$ of life).

IBM SPSS Version 20 was used to analyse the data, frequency and cross tabulation and Fisher exact $t$ test was used to see the significant association among variables. $\mathrm{P}$ value of $<0.05$ was considered significant.

\section{RESULTS}

There were total 98 cases of PA during the six months study period. The ratio of male:female was 1.45:1. The pie-chart in Figure 1 indicates that out of 98 cases of PA with HIE, 21\% had HIE grade I, $69 \%$ grade II HIE, and $10 \%$ had Grade III. Table 1 shows that among the cases, $71 \%$ had one minute APGAR $\leq 3$, only $17 \%$ of cases had five minute APGAR $\leq 3$, and $77 \%$ had five minutes APGAR 4-6. In our study, $6 \%$ of the cases showed good Apgar at five minutes of life but were still included in cases due to consistent finding of PA in physical examination and laboratory findings like ABG. Among 98 cases, mean one minute APGAR score was $2.85 \pm 1.18 \mathrm{SD}$ and mean 5 minute APGAR score was $4.80 \pm 1.3 \mathrm{SD}$. 


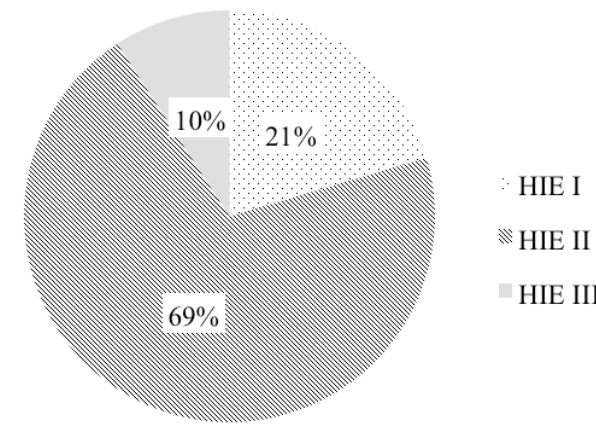

Table 1. Descriptive statistics of HIE grade

The cross-tabulation ( Table 2) of HIE grade and APGAR one minute shows that the cases of HIE are evenly distributed among various scores, and it represents that there is not a significant association between the low one minute APGAR score and HIE grades.

Table 3 represents the score among the HIE grade of the cases of APGAR $5 \mathrm{~min}$. The results show that there is no cases of score 1 in APGAR five minutes. Out of 20 cases of HIE I, 95\% cases have score 4-6/10. In HIE II, 14.5\% had 1-3 APGAR and $78 \%$ had $4-6 / 10$ APGAR. $78 \%$ of HIE cases had APGAR of $4-6 / 10$. This represents that there is significant association between the low five minute APGAR score and HIE grades. Out of 98 HIE cases $79.6 \%$ survived and $20.4 \%$ died during course of treatment. Mortality pattern among all three grades of HIE are shown in Table 4.
Table 1. Frequency table of the score of APGAR

\begin{tabular}{|lrrrr|}
\hline \multirow{2}{*}{ Score } & \multicolumn{4}{c}{ APGAR } \\
\cline { 2 - 5 } & \multicolumn{2}{c}{ 1 minute } & \multicolumn{3}{c|}{ 5 minute } \\
\cline { 2 - 5 } & Frequency & \% & Frequency & $\%$ \\
\hline $\mathbf{1 - 3}$ & 70 & 71 & 17 & 17 \\
$\mathbf{4 - 6}$ & 28 & 29 & 75 & 77 \\
$\mathbf{7 - 1 0}$ & 0 & 0 & 6 & 6 \\
Total & 98 & 100 & 98 & 100
\end{tabular}

Table 4 shows that the percentage of mortality increases with increase in the level of HIE grade. It shows that more than half of the cases of HIE III suffered mortality i.e. $55.6 \%$. There is only one case of mortality among 20 cases of HIE I while $20.3 \%$ of HIE II cases suffered mortality. Table also indicates that the mortality is highly significant with HIE grade.

The contingency table 5 shows that out of 20 cases of HIE I, only $15 \%$ cases have renal involvement but in total nine cases of HIE III, renal involvement is seen in all cases. Similarly, $87 \%$ cases of HIE II have renal involvement. Table also indicates that the involvement of renal is high as the HIE Grade increases, and this is statistically significant with $p$ value is $0.00(<0.05)$.

In the crosstab (Table 6) of HIE grade in four categories shows that, out of 98 HIE cases 31 have deranged urea/creatinine only, 20 have decreased

Table 2. Cross-tabulation of APGAR 1 minute and HIE Grade

\begin{tabular}{|c|c|c|c|c|c|c|c|c|c|}
\hline \multirow[t]{2}{*}{ HIE Grade } & \multirow[t]{2}{*}{ Frequency } & \multicolumn{6}{|c|}{ APGAR $1 \mathrm{~min}$} & \multirow[t]{2}{*}{ Total } & \multirow[t]{2}{*}{ p value } \\
\hline & & 1 & 2 & 3 & 4 & 5 & 6 & & \\
\hline \multirow[t]{2}{*}{ HIE I } & Count & 1 & 6 & 6 & 6 & 0 & 1 & 20.0 & 0.08 \\
\hline & percent & $5.0 \%$ & $30.0 \%$ & $30.0 \%$ & $30.0 \%$ & $0.0 \%$ & $5.0 \%$ & $100 \%$ & \\
\hline \multirow[t]{2}{*}{ HIE II } & Count & 8 & 16 & 25 & 14 & 5 & 1 & 69 & \\
\hline & percent & $11.6 \%$ & $23.2 \%$ & $36.2 \%$ & $20.3 \%$ & $7.2 \%$ & $1.4 \%$ & $100 \%$ & \\
\hline \multirow[t]{2}{*}{ HIE III } & Count & 4 & 4 & 0 & 1 & 0 & 0 & 9 & \\
\hline & percent & $44.4 \%$ & $44.4 \%$ & $0.0 \%$ & $11.1 \%$ & $0.0 \%$ & $0.0 \%$ & $100 \%$ & \\
\hline Total & Count & 13 & 26 & 31 & 21 & 5 & 2 & 98 & \\
\hline
\end{tabular}


Table 3. Cross-tabulation of HIE Grade and APGAR 5 minute

\begin{tabular}{|c|c|c|c|c|c|c|c|c|c|c|}
\hline \multirow[t]{2}{*}{ HIE Grade } & \multirow[t]{2}{*}{ Frequency } & \multicolumn{7}{|c|}{ APGAR 5 min } & \multirow[t]{2}{*}{ Total } & \multirow[t]{2}{*}{ p value } \\
\hline & & 2 & 3 & 4 & 5 & 6 & 7 & 8 & & \\
\hline \multirow[t]{2}{*}{ HIE I } & Count & 0 & 0 & 3 & 11 & 5 & 1 & 0 & 20 & 0.007 \\
\hline & percent & $0 \%$ & $0 \%$ & $15 \%$ & $55 \%$ & $25 \%$ & $5 \%$ & $0 \%$ & $100 \%$ & \\
\hline \multirow[t]{2}{*}{ HIE II } & Count & 4 & 6 & 13 & 22 & 19 & 4 & 1 & 69 & \\
\hline & percent & $5.8 \%$ & $8.7 \%$ & $18.8 \%$ & $31.9 \%$ & $27.5 \%$ & $5.8 \%$ & $1.4 \%$ & $100 \%$ & \\
\hline \multirow[t]{2}{*}{ HIE III } & Count & 2 & 5 & 1 & 1 & 0 & 0 & 0 & 9 & \\
\hline & percent & $22.2 \%$ & $55.6 \%$ & $11.1 \%$ & $11.1 \%$ & $0 \%$ & $0 \%$ & $0 \%$ & $100 \%$ & \\
\hline Total & Count & 6 & 11 & 17 & 34 & 24 & 5 & 1 & 98 & \\
\hline
\end{tabular}

urine output, 21 have both deranged blood renal function test and urine output and the remaining 26 have none of these problems. Table also indicates that there is significant association of higher level HIE grade with presentation of renal involvement clinically as well as biochemically.

\section{DISCUSSION}

In our study period of six months, we encountered total 98 cases of PA in our institute. Like many other studies, our results also showed males preponderance over female with PA. The ratio of males : females was $1.45: 1$. Male predominance is seen in most of the studies, the reason behind might not be same but male sex is more vulnerable to disease like sepsis, perinatal asphyxia. Our results are consistent with studies done by safaa A Medani et al. where they found to have more affected males

Table 4. Cross-tabulation of HIE Grade and Mortality case

\begin{tabular}{|c|c|c|c|c|c|}
\hline \multirow{2}{*}{$\begin{array}{l}\text { HIE } \\
\text { grade }\end{array}$} & \multirow{2}{*}{$\begin{array}{l}\text { Frequ } \\
\text { ency }\end{array}$} & \multicolumn{2}{|c|}{ Mortality } & \multirow[t]{2}{*}{ Total } & \multirow{2}{*}{$\begin{array}{l}p \\
\text { value }\end{array}$} \\
\hline & & No & Yes & & \\
\hline \multirow[t]{2}{*}{ HIE I } & Count & 19 & 1 & 20 & 0.009 \\
\hline & percent & $95.0 \%$ & $5.0 \%$ & $100.0 \%$ & \\
\hline \multirow[t]{2}{*}{ HIE II } & Count & 55 & 14 & 69 & \\
\hline & percent & $79.7 \%$ & $20.3 \%$ & $100.0 \%$ & \\
\hline \multirow{2}{*}{$\begin{array}{l}\text { HIE } \\
\text { III }\end{array}$} & Count & 4 & 5 & 9 & \\
\hline & percent & $44.4 .0 \%$ & $55.6 .0 \%$ & $100.0 \%$ & \\
\hline Total & Count & 78 & 20 & 98 & \\
\hline
\end{tabular}

with $59 \%$ incidence in comparison to $41 \%$ females. $^{7}$

Out of 98 cases of PA with HIE, 20.4\% had HIE Grade I, 70.4\% had grade II HIE and 9.18\% had grade III HIE. Occurrence of PA is different in various studies. . $8,12,13$ but proportion of severe forms of HIE (i,e HIE III) is less in all the studies. Extensive newborn health awareness, trainings like HBB, NRP, IMNCI etc has developed skilled human resources that has improved the basic resuscitation skill, that might have decreased the incidence of severe brain damage.

A comparison of HIE grade and APGAR 1 minute shows that there is no significant association between the low 1 minute APGAR score and HIE grade. Whereas, there is significant association between the low 5 minute APGAR score and HIE

Table 5. Cross-tabulation of HIE Grade and Renal involvement

\begin{tabular}{|c|c|c|c|c|c|}
\hline \multirow{2}{*}{$\begin{array}{l}\text { HIE } \\
\text { Grade }\end{array}$} & \multirow{2}{*}{$\begin{array}{l}\text { Frequ } \\
\text { ency }\end{array}$} & \multicolumn{3}{|c|}{ Renal involvement } & \multirow{2}{*}{$\begin{array}{l}P \\
\text { value }\end{array}$} \\
\hline & & Yes & No & Total & \\
\hline \multirow[t]{2}{*}{ HIE I } & count & 3 & 17 & 20 & 0.00 \\
\hline & percent & $15.0 \%$ & $85.0 \%$ & $100.0 \%$ & \\
\hline \multirow[t]{2}{*}{ HIE II } & count & 60 & 9 & 69 & \\
\hline & percent & $87.0 \%$ & $13.0 \%$ & $100.0 \%$ & \\
\hline \multirow{2}{*}{$\begin{array}{l}\text { HIE } \\
\text { III }\end{array}$} & count & 9 & 0 & 9 & \\
\hline & percent & $100.0 \%$ & $0.0 \%$ & $100.0 \%$ & \\
\hline Total & count & 72 & 26 & 98 & \\
\hline
\end{tabular}


Table 6. Cross-tabulation of HIE Grade among the categories of Renal involvement

\begin{tabular}{|c|c|c|c|c|c|c|c|}
\hline \multirow{2}{*}{$\begin{array}{l}\text { HIE } \\
\text { grade }\end{array}$} & \multirow[t]{2}{*}{ Frequency } & \multicolumn{4}{|c|}{ Renal involvement } & \multirow[t]{2}{*}{ Total } & \multirow{2}{*}{$\begin{array}{c}\mathbf{p} \\
\text { value }\end{array}$} \\
\hline & & $\begin{array}{l}\text { Urea/creatinine } \\
\text { derange only }\end{array}$ & None & $\begin{array}{l}\text { Decreased urine } \\
\text { output only }\end{array}$ & Both & & \\
\hline \multirow[t]{2}{*}{ HIE I } & Count & 3 & 17 & 0 & 0 & 20 & 0.00 \\
\hline & percent & $15.0 \%$ & $85.0 \%$ & $0.0 \%$ & $0.0 \%$ & $100.0 \%$ & \\
\hline \multirow[t]{2}{*}{ HIE II } & Count & 26 & 9 & 17 & 17 & 69 & \\
\hline & percent & $37.7 \%$ & $13.0 \%$ & $24.6 \%$ & $24.6 \%$ & $100.0 \%$ & \\
\hline \multirow[t]{2}{*}{ HIE III } & Count & 2 & 0 & 3 & 4 & 9 & \\
\hline & percent & $22.2 \%$ & $0.0 \%$ & $33.3 \%$ & $44.4 \%$ & $100.0 \%$ & \\
\hline Total & Count & 31 & 26 & 20 & 21 & 98 & \\
\hline
\end{tabular}

grade. One minute APGAR score is not a reliable marker for brain involvement and thus continuous score of APGAR at 5 minutes add more value for its association with brain involvement. These findings are consistent with various other similar studies. ${ }^{11,12}$ Studies done by Abbot R Laptook et al. has shown that poor APGAR in 1 minute has progressively shifted to higher values at five and 10 minutes and they have recommended importance of 10 minute APGAR score in neurological outcome. $^{12}$

Out of 98 HIE cases $79.6 \%$ survived and 20.4\% died during course of treatment in our centre during the study period. The percentage of mortality increases with increase in the level of HIE grade. It shows that more than half of the cases of HIE III had mortality i.e. $55.6 \%$. This indicates that the mortality is highly significant with HIE grade. Severe brain involvement in PA reflects impairment in diving reflex where non vital organs are already being compromised and in many cases even other vital organs are being compromised. ${ }^{2,4}$ Thus mortality tends to be high in that group. Though mortality in studies done in developed country might be different, due to advanced case management and application of therapeutic hypothermia, ${ }^{5}$ but mortality in developing countries remain similarly high.

In this study all the HIE III cases had renal involvement, $87 \%$ of HIE II had some form of renal involvement. This indicates that the involvement of renal is high as the HIE grade increases and this is statistically significant as well. Our result is consistent various studies. ${ }^{8,13}$ This, in fact is well explained by the pathogenesis of perinatal asphyxia that in those cases with brain involvement in perinatal asphyxia, non-vital organs are already being compromised and kidney is the most common organ involved.

In our setting, due to high volume deliveries and staff shortage, it is very difficult to calculate urine output of each patient, so very sick cases are catheterised for urinary output measurement while rest of the patient's urine output is measured by counting the number of wet nappies. Also blood test for renal function are delayed beyond 48 hours due to technical problems like unavailability of visitors on time for sample transport, which causes delay in estimation of renal involvement. Thus we have included all suggestive measures to broaden our scope to catch the renal involvement.

In our HIE cases, renal involvement could be categorised into four possible situations; it shows that, out of 98 HIE cases 31 had deranged urea/ creatinine only, 20 had decrease urine output, 21 had both deranged blood test and urine output and the remaining 26 had none of these problems. This indicates that there is significant association of higher level HIE grade with presentation of renal involvement clinically as well as biochemically. Similar findings were found in studies done by Safaa A Medani et al., where their HIE case had 
AKI up to $54 \%$. $^{7}$ Among cases of studies done by Ganavi Ramagopal et al. ARF was seen in $75 \%{ }^{8}$ Similar results are seen in various studies as well. ${ }^{14,17,20}$ Highest number (86\%) of ARF was seen in neonates with HIE III in a study done by Hadzimuratovi Emnia et al., which indicated more renal problem in higher grades of HIE. ${ }^{13}$ Renal involvement is in perinatal asphyxia is obvious after second day. Anticipation of renal involvement in various way (i,e decreased urine output or deranged urea/ creatinine or both) should be kept in cases of perinatal asphyxia with any degree of HIE. In developed countries, early marker of renal involvement is available but in developing country like ours should be more vigilant with the urine output and RFTs. Our study also has many limitations as it was done in single centred and the small sample size, further studies with larger sample size is need. Though the cases of this study were taken at a time where further studies excluding sepsis in HIE cases is highly recommended.

\section{CONCLUSIONS}

Renal involvement is very common in cases of perinatal asphyxia, and severity of renal involvement increases as the HIE grading increases.

\section{REFERENCES}

1. Unicef, Maternal and Newborn Health Disparities in Nepal: Key facts. 2015

2. Askenazi DJ, Goldstein SL. Renal conditions, Manual of Neonatal care, $6^{\text {th }}$ edition, Wolters Kluwer/Lippincott William\& Wilkins, pg 350.

3. Sreedharan R, Avner ED. Nephrology, Chapter 535 Renal Failure, Pg 2541, Nelson Textbook of Pediatrics 20th Edition, ELSEVIER, 2016

4. Askenazi D, smith LB. Acute Kidney Injury and Chronic Kidney Disease, Chapter 85, Avery's disease of the Newborn 9th edition ,ELSEVIER Saunders, 2012

5. Selewski DT, Charlton JR, Jetton JG, Guillet R, Mhanna MJ, Askenazi DJ et al. Neonatal acute kidney injury. Pediatrics. 2015;136(2):463-73. DOI: https://doi.org/10.1542/peds.2014-3819

6. Alaro D, Bashir A, Musoke R, Musoke R, Wanaiana L. Prevalence and outcomes of acute kidney injury in term neonates with perinatal asphyxia. Afr Health Sci. 2014;14(3):682-8. DOI: 10.4314/ahs.v14i3.26

7. Medani SA, Kheir AEM, Mohamed MB. Acute kidney injury in asphyxiated neonates admitted to a tertiary neonatal unit in Sudan. Sudan J Paediatr. 2014;14(2):29-34.

8. Ramagopal G, Narayana G, Premalatha R, Gangadha RB. Incidence of Acute Renal Failure( ARF) in birth asphyxia and its correlation with hypoxic Ischemic Encephalopaty (HIE) Staging, Indian J Neonatal Med Res. 2016;4(2):1-4. DOI: IJNMR/2016/18312.2118

9. Nouri S, Mahdhaoui N, Beizig S, Zakhama R, Salem N, Ben Dhafer S, et al. Acute renal failure in full term neonates with perinatal asphyxia. Prospective study of 87 cases. Arch Pediatr. 2008;15(3):229-35.DOI: 10.1016/j.arcped. 2008.01.011. Epub 2008 Mar 7.

10. Apgar V. A Proposal for a New Method of Evaluation of the Newborn Infant. Curr Res Anesth Analg. 1953;32(4): $260-67$.

11. Aliyu I, Lawal TO, Onankpa B. Hypoxic-ischemic encephalopathy and the Apgar scoring system: The experience in a resource-limited setting. J Clin Sci. 2018;15:18-21. DOI: 10.4103/jcls.jcls_102_17

12. Laptook AR, Shankaran S, Ambalavanan N, Carlo WA, McDonald SA, Higgins RD, et al. Outcome of Term Infants using Apgar Scores at 10 Minutes following Hypoxic-Ischemic Encephalopathy. Pediatrics. 2009;124(6):1619. doi: 10.1542/peds.2009-0934. 
13. Hadzimuratovic E, Skokic F, Hadzimuratovic A, Nazdrajic AH, Mujic M, Hadzimuratovic AD. Acute renal failure in term newborn following perinatal asphyxia. SANAMED. 2017;12(1):11-4. DOI: http://dx.doi.org/10.24125/ sanamed.v1i1.162

14. Aslam M, Arya S, Chellani H, Kaur C. Incidence and predictors of acute kidney injury in birth asphyxia in a Tertiary Care Hospital. J Clin Neonatol. 2017;6:240-4. DOI: 10.4103/jen.JCN_53_17

15. Youssef D, Abd-Elrahman H, Shehab MM, Abd-Elrheem M. Incidence of acute kidney injury in the neonatal intensive care unit. Saudi J Kidney Dis Transpl. 2015;26:67-72. DOI: 10.4103/1319-2442.148738

16. Jayashree G, Dutta AK, Sarna MS, Saili A. Acute renal failure in asphyxiated newborns. Indian Pediatr. 1991;28(1): $19-23$.

17. Agrawal S, Chaudhuri PK, Chaudhary AK, Kumar D. Acute kidney injury in asphyxiated neonates and its correlation to hypoxic ischemic encephalopathy staging. Indian J Child Health. 2016; 3(3):254-257.

18. Durkan AM, Alexander RT. Acute Kidney Injury Post Neonatal Asphyxia, J Pediatr. 2011;158(2):29-33. DOI: 10.1016/j.jpeds.2010.11.010

19. Roberts DS, Haycock GB, Dalton RN, Turner C, TomlinsonP, Stimmler L, et al. Prediction of acute renal failure after birth asphyxia. Arch Dis Child. 1990; 65(10):1021-8. DOI: 10.1136/adc.65.10_spec_no.1021

20. Gupta BD, Sharma P, Bagla J, Parakh M, Soni JP. Renal failure in asphyxiated neonates. Indian Pediatr. 2005;42(9): 928-34. PMID: 16208054 